\title{
Investigating fish behavioural responses to LED lights in trawls and potential applications for bycatch reduction in the Nephrops-directed fishery
}

Melli, Valentina; Krag, Ludvig Ahm; Herrmann, Bent; Karlsen, Junita Diana

Published in:

ICES Journal of Marine Science

Link to article, DOI:

10.1093/icesjms/fsy048

Publication date:

2018

Document Version

Peer reviewed version

Link back to DTU Orbit

Citation (APA):

Melli, V., Krag, L. A., Herrmann, B., \& Karlsen, J. D. (2018). Investigating fish behavioural responses to LED lights in trawls and potential applications for bycatch reduction in the Nephrops-directed fishery. ICES Journal of Marine Science, 75(5), 1682-1692. https://doi.org/10.1093/icesjms/fsy048

\section{General rights}

Copyright and moral rights for the publications made accessible in the public portal are retained by the authors and/or other copyright owners and it is a condition of accessing publications that users recognise and abide by the legal requirements associated with these rights.

- Users may download and print one copy of any publication from the public portal for the purpose of private study or research.

- You may not further distribute the material or use it for any profit-making activity or commercial gain

- You may freely distribute the URL identifying the publication in the public portal 

1

Investigating fish behavioural responses to LED lights in trawls and potential applications for bycatch reduction in the Nephrops-directed fishery.

(1)

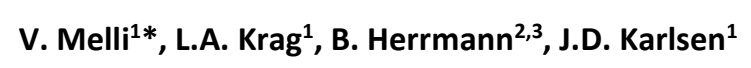

${ }^{1}$ DTU Aqua, National Institute of Aquatic Resources, North Sea Science Park, DK-9850, Hirtshals, Denmark ${ }^{2}$ SINTEF Fisheries and Aquaculture, Willemoesvej 2, DK-9850 Hirtshals, Denmark ${ }^{3}$ University of Tromsø, Breivika, N-9037 Tromsø, Norway

Email addresses: VM - $\underline{\text { vmel@aqua.dtu.dk; LAK - lak@aqua.dtu.dk; }}$ BH Bent.Herrmann@sintef.no; JDK - juka@aqua.dtu.dk

Correspondence: Valentina Melli, DTU Aqua, National Institute of Aquatic Resources, North Sea Science Park, DK-9850, Hirtshals, Denmark.

Telephone: +45 35883270; e-mail: vmel@aqua.dtu.dk

(1)

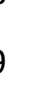

0

1

2

33

4

5

6
9 30 


\section{Abstract}

34 Light Emitting Diodes (LED) have been tested in trawl fisheries to reduce the bycatch of unwanted species through behavioural stimulation. Previous studies used LED lights to either highlight escaping routes or increase the contact rate with square mesh panels. However, phototactic responses (moving towards or away from light sources) to LED lights could also be exploited to separate species during the catching process. We investigated if either positive or negative phototaxis can be triggered in fish to modify their vertical distribution in the aft section of a horizontally separated trawl codend. The aim was to separate fish into the upper compartment and Nephrops (Nephrops norvegicus) into the lower compartment. We conducted two different experiments in front of the separation into compartments, inserting green LED lights in the upper and lower netting panel, respectively. Species vertical separation was analysed and compared in two identical trawls towed in parallel, one equipped with lights and one without. Significant differences in species vertical distribution were observed; however, most effects resulted in increased number of individuals entering the lower compartment. No clear species-specific phototactic response was identified and the results highlighted the challenges of inferring behavioural responses in trawls. Future steps required to improve the understanding of fish reactions to artificial lights are discussed.

\section{Keywords}




\section{Introduction}

Artificial light affects the behaviour of many species, both terrestrial and marine. Most species are known to respond to light by either positive or negative phototaxis, i.e. moving respectively towards or away from the light source (Pascoe, 1990; Marchesan et al., 2005). In the marine environment phototaxis has been observed in both invertebrates and teleost fish (Verheijen, 1960) and described as the consequence of several behavioural responses. Positive phototaxis can result from e.g. searching for species-specific preferred light levels, disorientation or prey availability in proximity of the light source (Verheijen, 1960; Marchesan et al., 2005; Arimoto et al., 2010). Negative phototaxis has also been related to light level preferences, as well as to anti-predator avoidance behaviours (Marchesan et al., 2005; Ryer et al., 2009). An approaching light can be visually interpreted as the increasing proximity of an unknown danger, which frequently triggers anti-predator responses (Domenici, 2002). In general, when a phototactic response occurs, whether it is positive or negative phototaxis, it is species-specific and depends on environmental factors and the physical characteristics of the light source (Marchesan et al., 2005).

Species response to artificial lights found an early application in fisheries. Positive phototaxis has been used for centuries in night fishing to catch cephalopods and schooling fish (Ben-Yami, 1976; Inada and Arimoto, 2007; Arimoto et al., 2010). Over time, the use of lights as lures has been adopted by a variety of fisheries, both artisanal and industrial, such as purse seines, gillnets, longlines, and pots (Ben-Yami, 1976; Bryhn et al., 2014; 
Nguyen et al., 2015; Nguyen et al., 2017). The lights used in fisheries have also developed accordingly, growing in intensity and endurance, and becoming cheaper and more available for individuals and whole industries. Recently, artificial lights have aroused interest from researchers in gear technologies as a potential stimulus to improve gear selectivity and reduce the bycatch of unwanted species. For example, lights attached to a partially raised footrope in a shrimp trawl allowed fish to escape below it, resulting in a reduction of fish bycatch (Hannah et al., 2015). Inside a midwater trawl targeting Pacific hake (Merluccius productus) escape windows with lights were preferred by Chinook salmon (Oncorhynchus tshawytscha; Lomeli and Wakefield, 2014). Artificial lights used as visual deterrents in gillnets have significantly reduced the bycatch of sea turtles, without affecting the catch of the target fish species (Wang et al., 2010).

Despite these successes, species-specific behavioural responses to light stimuli are still not fully understood and the application of light in trawls often produces unexpected results. Hannah et al. (2015) attached lights to a grid in a shrimp trawl to visually stimulate fish to follow the grid to an escape opening. As a result, most fish, which previously tried to avoid the grid, swam through it and were caught. Similar results were obtained by Larsen et al. (2017), who used lights to highlight the escape opening in a Nordmøre grid. Grimaldo et al. (2017) tested lights on free moving ropes in a square mesh section to increase the contact probability of cod (Gadus morhua) and haddock (Melanogrammus aeglefinus) with the netting; thus, enhancing their escape rate. Video observations throughout the experiment highlighted different behaviours in the two gadoids, with neither of them being useful to improve their escape rate. Haddock showed a panic reaction to the moving lights, which prevented individuals from approaching the meshes 
at the correct angle to escape. In contrast, cod remained stationary in front of the lights and seemed to be unaffected by them. These examples suggest that the complexity of stimuli received by fish inside a trawl, such as visual and mechanical obstacles (e.g. a grid) and the background illuminated (e.g. netting), might overcome potential phototactic responses. All of these studies have applied lights directly in the area providing an escape route (i.e. open window, square mesh panel, etc.) where an immediate response is necessary for fish to escape. It is not known if lights can be used to gradually influence species position before the point of interest.

In this study we investigated if: i) phototaxis can be exploited to modify fish vertical distribution before a separation into two stacked compartments; and ii) either positive or negative phototaxis is efficient in leading fish into the upper compartment. We used the Nephrops (Nephrops norvegicus) directed trawl fishery as a case study, as the horizontally divided design has proved to have a great potential for reducing bycatch in this fishery (Main and Sangster, 1985a; Krag et al., 2009; Karlsen et al., 2015). Separating fish from Nephrops has two major advantages: i) fish in the upper compartment can be selected out with a larger mesh size or released, in accordance with quota availability (Krag et al., 2008; Frandsen et al., 2010), and ii) the quality of the fish bycatch can benefit from less interaction with shellfish; hence, reducing internal and external damage (Karlsen et al., 2015). Due to the small mesh sizes used to retain the target species, the fish bycatch in this fishery includes commercial and undersized individuals of several species (Kelleher, 2005). Because Nephrops is relatively passive inside the trawl, with most individuals rolling along the bottom panel towards the codend (Main and Sangster, 1985b), actively swimming fish species can be vertically separated from it. Nevertheless, this separation 
depends on the vertical distribution of fish in the funnel and on their swimming capacity;

thus, it varies among species and length classes (Main and Sangster, 1985a; Ferro et al., 2007; Krag et al., 2009; Rosen et al., 2012). Species that have a tendency to stay close to the bottom panel, e.g. cod and flatfish, need to be stimulated to rise or they will most likely enter the lower compartment together with the crustaceans. Thus, visual and mechanical stimulations have been tested to modify species vertical separation. For example, the heights of the entrance to each compartment have been optimized to make the upper compartment appear like the clearest path (Glass et al., 1993; Krag et al., 2009). Visual stimuli, such as a black tunnel (He et al., 2008) at the entrance of the lower compartment have successfully changed the vertical preference of cod. Similarly, mechanical stimuli such as frames and grids, which obstruct the entrance to the lower compartment, have succeeded in separating most fish from Nephrops (Karlsen et al., 2015). However, to the best of our knowledge, nobody has previously attempted to use artificial light phototaxis to influence species vertical separation.

\section{Materials and methods}

\subsection{Baseline trawl}

The horizontally separated trawl used in this study was an adaptation of a trawl tested by Karlsen et al. (2015). We used two identical Combi trawls (40 m long footrope, 420 meshes fish circle, $80 \mathrm{~mm}$ mesh size) made of two net panels before the separation and four net panels after the separation into an upper and lower compartment by a horizontal net panel. Both the compartments had nominal $40 \mathrm{~mm}$ meshes $(41.65 \pm 1.33$ dry; $1.8 \mathrm{~mm}$ twine) diamond that were turned 45 degrees to obtain square meshes. The vertical separation was positioned in the transition between the tapered and non-tapered 
sections of the gear, where the inclination of the lower netting of the trawl ends (Fig. 1).

Respect to the design tested by Karlsen et al. (2015), part of the tapered section was cut out to increase the circumference before the separation from 100 to 140 meshes, which extended the vertical space available to fish in this part of the gear. The entrance of the upper compartment was approximately $60 \mathrm{~cm}$ high (based on underwater video observations) and sustained by 12 floats ( $720 \mathrm{~g}$ lift) inserted outside the upper netting (Fig. 1). The entrance of the lower compartment was fixed by two frames, $30 \mathrm{~cm}$ high and $90 \mathrm{~cm}$ wide ( $\varnothing 20 \mathrm{~mm}$ stainless steel pipes) which prevented the lower compartment from collapsing (Fig. 1). The frame at the entrance of the lower compartment included two vertical bars (30 $\mathrm{cm}$ apart) to visually and mechanically stimulate fish to swim into the upper compartment, following Krag et al. (2009).

FIGURE 1

\subsection{Experimental design}

Phototactic responses were stimulated in the trawl funnel, before the point of vertical separation, using green Electralume ${ }^{\circledR}$ LED lights (Lindgren-Pitman, Pompano Beach, FL, USA; 0.5-2.0 Ix). These lights have been used in other studies (Hannah et al., 2015; Grimaldo et al., 2017; Nguyen et al., 2017) because they are compact, inexpensive, pressure resistant, and with a battery life of approximately 350 hours. The green colour of these lights (centred at $540 \mathrm{~nm}$ ) is considered ideal for sea water in coastal temperate areas, because it is less easily absorbed, and thus penetrates deeper. Moreover, some of the target species of the study, like cod, have been proven to have a primary sensitivity peak that occurs at $490 \mathrm{~nm}$ (blue/green light; Anthony and Hawkins, 1983). 
To investigate potential phototactic responses, we conducted two experiments. In

171 Experiment 1 we attached 10 Electralume ${ }^{\circledR}$ LED lights to the lower netting panel in the aft part of the tapered section and in Experiment 2 we placed them in the corresponding upper netting panel (Fig. 1). In both experiments the 10 lights were attached to two $5 \mathrm{~m}$

174 long polypropylene ropes (8 $\mathrm{mm}$ diameter, 3 strands), which were fixed respectively to the lower or upper netting panel with cable ties. The lights were blocked in continuous

176 mode and directed towards the forward part of the trawl. Electralume ${ }^{\circledR}$ LED lights emit

177 light in all directions except for the rear, with the intensity being higher laterally at about

17845 degrees respect to the central axis (V. Melli, personal observations). The distance between the last three lights of each rope was reduced to increase the strength of the stimulus while approaching the vertical separation (Fig. 1).

\subsection{Sea trial}

The sea trial was conducted on 5-20 September 2016 with the research vessel "Havfisken" (17 m, $373 \mathrm{~kW})$. We used three-wire, twin trawls towed in parallel, with one trawl working as the baseline for species separation and the other as the test equipped with the lights. Using this setup, it would normally be assumed that the two trawls encountered the same fish population. However, due to a second experiment located in the forward part of the trawl (Melli et al., 2017), the population entering the baseline and test trawls differed and the two gears were thus analysed separately. To avoid any trawl-dependent effect on the vertical separation of the species, the position of the light treatment was shifted from one trawl to the other approximately every sixth haul. Two Type 2 Thyborøn doors $\left(1.78 \mathrm{~m}^{2}\right.$, $197 \mathrm{~kg}$ ), with an additional weight of $25 \mathrm{~kg}$, and a 400-kg triangular central clump were used to spread the twin trawl-rig. Doors and clump were equipped with distance sensors 
193 (Simrad PI) to monitor each trawl spread in the twin-rig. The trawls were rigged with 75 $194 \mathrm{~m}$ long single wire sweeps with $4.3 \mathrm{~cm}$ (diameter) rubber discs. The distance between the 195 two trawls' mouths was estimated to be approximately $50 \mathrm{~m}$. Fishing was conducted in 196 commercial Nephrops and fish grounds in the Skagerrak Sea, at depths between 45 and $19786 \mathrm{~m}$. According to the optical classification of this area (coastal waters type 1; Aarup et 198 al., 1996), the range of depths was out of the Eutrophic zone (i.e. where less than $1 \%$ of 199 the surface light reaches). To be representative of commercial fishing conditions, experimental hauls were performed at both day time, between $1 \mathrm{~h}$ after sunrise and $1 \mathrm{~h}$ 201 before sunset and night time, between $1 \mathrm{~h}$ after sunset and $1 \mathrm{~h}$ before sunrise. The catch in each compartment was weighted and sorted by species. The total length of all commercial fish species and the carapace length of Nephrops were measured and rounded down to the nearest $\mathrm{cm}$ and $\mathrm{mm}$, respectively.

The aim of the study was to separate fish from Nephrops; therefore, we defined the vertical separation efficiency $V S(I)$ as the probability of finding a fish of length $I$ in the upper compartment, given that it was observed in the upper or lower compartment. For each experiment ( 1 and 2 ) and each species, VS(I) was estimated for the baseline and test trawls separately based on the catch data summed over all hauls following the method described below.

Let $n U_{l i}$ and $n L_{l i}$ denote the number of individuals of length class / caught and measured in each of the two compartments in each haul $i$, respectively. Then, $V S_{l i}$ is the proportion of fish of length / caught in the upper compartment compared to the total in a haul $i$ : 


$$
V S_{l i}=\frac{\frac{n U_{l i}}{q U_{i}}}{\frac{n U_{l i}}{q U_{i}}+\frac{n L_{l i}}{q L_{i}}}
$$

where $q U_{i}$ and $q L_{i}$ are the sampling factors (i.e. the proportion between the weight of the sample length-measured and the weight of the total catch of that species) in the upper and lower compartments, respectively, in haul $i$.

Assuming that the vertical separation summed over the hauls is representative of how the vertical separation would perform on average, an estimation of the average vertical separation can be obtained by pooling the data from the different hauls. A parametric model for $V S(I)$ is defined by $V S(I, v)$, where $\boldsymbol{v}$ is a vector consisting of the parameters of the model. The analysis is therefore reduced to a maximization problem, to estimate the values of the parameters $\boldsymbol{v}$ which make the observed experimental data averaged over hauls most likely, assuming that the model is able to describe the data sufficiently well. Thus, the maximum likelihood function for binomial data (2) is minimized with respect to $\boldsymbol{v}$, which is equivalent to maximizing the probability for the observed data.

$$
g(\boldsymbol{v})=-\sum_{l} \sum_{i=1}^{h}\left\{\frac{n U_{i l}}{q U_{i}} \times \ln (V S(l, \boldsymbol{v}))+\frac{n L_{i l}}{q L_{i}} \times \ln (1.0-V S(l, \boldsymbol{v}))\right\}
$$

where the summations are made over length classes $/$ and the $h$ hauls belonging to the case analyzed. To find a model for $\operatorname{VS}(I, \boldsymbol{v})$ that is sufficiently flexible to account for the trends in the experimental data we adapted a model often applied in catch comparison studies to determine the efficiency and selectivity of fishing gears (Krag et al. 2014, 2015):

$V S(l, \boldsymbol{v})=\frac{\exp (f(l, v))}{1.0+\exp (f(l, v))}$

where $f$ is a polynomial of order $k$ with coefficients $v_{0}, \ldots, v_{k}$ so $v=\left(v_{0}, \ldots, v_{k}\right) . f(l, v)$ is determined as follows: 
$f(l, v)=\sum_{i=0}^{4} v_{i} \times\left(\frac{l}{100}\right)^{i}=v_{0}+v_{1} \times \frac{l}{100}+v_{2} \times \frac{l^{2}}{100^{2}}+\cdots+v_{4} \times \frac{l^{4}}{100^{4}}$

Leaving out one or more of the parameters $v_{0} \ldots v_{4}$ in (4) provided 31 additional models

that were considered as potential models to describe VS $(I, v)$. Based on these models, model averaging was applied to describe $V S(I, v)$ according to how likely the individual models were when compared to each other (Burnham and Anderson, 2002). We called the resulting model the combined model. In the combined model the individual models were ranked and weighted according to their Akaike information criterion (AIC) values (Akaike, 1974; Burnham and Anderson, 2002). Models with AIC values within +10 of the value of the model with the lowest AIC were considered to contribute to $V S(I, v)$ based on the procedure described by Katsanevakis (2006) and Herrmann et al. (2017). The ability of the combined model to describe the experimental data was assessed based on the $p$ value and the model deviance respect to the degrees of freedom (DoF). The $p$-value in this analysis expresses the likelihood of obtaining at least as big a discrepancy as that observed between the fitted model and the experimental data by coincidence. Therefore, for the combined model to be a candidate model, the $p$-value should not be below 0.05 and the deviance should be in the same order of the DoF (Wileman et al., 1996). In case of poor fit statistics ( $p$-value $<0.05$; deviance $>>$ DoF), the model curve plots and the residuals were examined to determine whether there were structural problems in describing the experimental data with the combined model or if it was a case of data overdispersion (Wileman et al., 1996). The value of $\operatorname{VS}(I, v)$ for the combined model represents the probability of finding a fish of length I in the upper compartment. A value above 0.5 indicated a higher probability of finding the individual in the upper compartment. However, to indicate that the proportion of a species entering a given compartment is 
higher than the height of the opening of that compartment relative to the total section at the point of separation, we adopted the term "preference". Considering that the upper compartment accounted for $67 \%$ of the total section, only values of $V S(I, v)$ above 0.67 were consider to represent a significant difference in vertical distribution between the two compartments. Similarly, a value significantly below 0.67 would imply a preference for the lower compartment.

Confidence intervals ( $\mathrm{Cls}$ ) for the length-dependent vertical separation efficiency were estimated using a double bootstrap method (Millar, 1993). The procedure accounted for the uncertainty due to between-haul variation in the vertical separation efficiency by selecting $h$ hauls with replacement from the $h$ hauls available for the specific case investigated during each bootstrap repetition. Within-haul uncertainty in the size structure of the catch data was accounted for by randomly selecting individuals with replacement from each haul and each compartment separately. The number of fish selected from each haul was the number of fish length-measured in that haul in each compartment. For each species, only hauls containing at least 10 individuals in the upper and lower compartments summed were included, following Krag et al. (2014). A total of 1,000 bootstrap repetitions were performed and Efron 95\% $\mathrm{Cls}$ (Efron, 1982) were calculated for the vertical separation curve. By incorporating the combined model approach in each of the bootstrap repetitions we accounted for the additional uncertainty on the vertical separation efficiency due to uncertainty in model selection (Herrmann et al., 2017). All the analyses were performed using the software SELNET (Herrmann et al., 2012). 
The length-based, average vertical separation efficiency of the baseline trawl, VSB(I), and test trawl, VST(I), for each experiment ( 1 and 2 ) was estimated with $95 \%$ Cls according to the procedure described in the previous section. In principle, we could have inferred whether the treatment had any significant effect on the vertical separation by overlapping the Cls obtained for $\operatorname{VSB}(I)$ and $\operatorname{VST}(/)$. However, this approach does not take full advantage of our experimental design, in which the baseline and test trawl are fished simultaneously in parallel and are therefore subjected to the same varying fishing conditions between hauls. Therefore, instead of applying the analysis separately for the baseline and test trawl, as described in the previous section, we synchronized the hauls selected for the outer bootstrap loop for the baseline and test trawls and for each bootstrap we calculated the treatment effect $\Delta \mathrm{VS}(I, v)$ on the vertical separation by:

$\Delta V S(l, v)=V S B(l, v)-V S T(l, v)$

Through this synchronization in the haul selection and the direct calculation of $\Delta \mathrm{VS}(I, \boldsymbol{v})$ in each bootstrap we removed part of the between-haul variation in vertical separation efficiency and increased the power of the analysis to infer the treatment effect. $\Delta \mathrm{VS}(I, v)$ can span between -1 and 1 , where positive values mean that more individuals of length I are entering the upper compartment in response to the lights. In contrast, negative values mean more individuals are entering the lower compartment. For those length-classes in which the $95 \% \mathrm{Cls}$ for $\Delta \mathrm{VS}(I, \boldsymbol{v})$ did not contain 0.0 , we determined a significant effect of the light treatment.

\section{Results}

A total of 18 hauls were conducted, ten hauls for Experiment 1 and eight hauls for Experiment 2 (Table 1). The towing time varied between 30 and $120 \mathrm{~min}$ according to the 
catch observed with the vessel's eco-sounder, as it was imperative for a correct interpretation of the vertical separation efficiency that no fish were found ahead of the separation into two compartments when hauling the catch.

Sufficient data for analysis were collected for six commercial species (Table 2): the target species, Nephrops; three roundfish species, cod (Gadus morhua), haddock (Melanogrammus aeglefinus), and whiting (Merlangius merlangus); and two flatfish species, plaice (Pleuronectes platessa) and lemon sole (Microstomus kitt). Due to the period of the study, very few fish were encountered while fishing in Nephrops grounds. Therefore, because the strongest reactions to the lights were expected from fish, only a few hauls during Experiment 1 were used to verify the effect on Nephrops (Table 2).

317 Fit statistics for each of the models are reported in Table 3. In most cases, $p$-values were above 0.05 , indicating that the model could be trusted to describe the experimental data. Four models in each experiment had poor fit statistics $(p<0.05$, deviance $>>$ DoF): in Experiment 1 the models for the baseline trawl of haddock and whiting and for the test trawl for cod and Nephrops; and in Experiment 2 the models for haddock and whiting in both the baseline and test trawls (Table 3). For these cases the residual deviations between the data and the modelled curves were investigated. No systematic structure was detected. We considered the low $p$-values to be a consequence of overdispersion in the data caused by the sub-sampling (e.g. whiting and Nephrops) and the high dispersion in those length classes with relative low frequency. Such cases are frequent and have been 
reported before (e.g. Larsen et al., 2017). Therefore, we were confident that all the models could be used to describe the vertical separation efficiency. The results for both experiments are hereafter presented by species to facilitate the interpretation of changes in vertical separation efficiency.

TABLE 3

\section{Nephrops}

The separation efficiency curves of both the baseline and test trawls described overall the experimental data well (Fig. 2). Where fewer individuals were caught, an increasing binominal noise is observed through the increasing size of the Cls. In both trawls, Nephrops showed a strong, significant preference for the lower compartment, with Cls well below 0.67 for all length classes represented (18-62 mm; Fig. 2). The difference in separation efficiency ( $\Delta V S$ ) indicated a significant effect of the light treatment (Fig. 2, Delta). When lights were inserted in the lower panel, Nephrops between 40 and $55 \mathrm{~mm}$ were found in greater numbers in the lower compartment.

FIGURE 2

\section{Cod}

343 The separation efficiency curves for cod described the main trends in the data relatively well in both experiments (Fig. 3). Few individuals above $40 \mathrm{~cm}$ were caught; thus, the $\mathrm{Cls}$ vertical preference, with smaller individuals more frequently entering the lower compartment. In the baseline trawl, cod of $25-59 \mathrm{~cm}$ and $30-43 \mathrm{~cm}$ in Experiment 1 and 
preference disappeared in the test trawl with the light treatment in either position. LED lights in the lower panel (Experiment 1) significantly and negatively affected cod of length

$351 \quad 11-18 \mathrm{~cm}$ and $28-43 \mathrm{~cm}$ (Fig. 3, Delta), corresponding to the two main bulks of length classes caught during the trial. Lights in the upper panel (Experiment 2) did not cause a significant change in vertical distribution, with the exception of, the $30-\mathrm{cm}$ length class which entered more frequently the lower compartment.

FIGURE 3

\section{Haddock}

The separation efficiency curves for haddock represent the experimental data reasonably well, without systematic deviations between the experimental points and the modelled curves (Fig. 4). Few individuals above $40 \mathrm{~cm}$ were caught; thus, the Cls were broad for the biggest length classes. A large proportion of haddock entered the upper compartment, but a significant preference for this compartment was detected only for few length classes, $18-26 \mathrm{~cm}$ and $25-32 \mathrm{~cm}$ in the baseline trawl of Experiment 1 and 2, respectively. Lights in the lower panel (Experiment 1) did not cause any change in haddock's vertical distribution lights inserted in the upper panel (Experiment 2) significantly and positively affected individuals of 33-42 cm (Fig. 4, Delta).

FIGURE 4

\section{Whiting}

The separation efficiency curves for whiting described the main trends in the data very well, with relatively small Cls for length classes with strong data $(20-27 \mathrm{~cm})$ (Fig. 5). 


\section{FIGURE 6}

FIGURE 5

\section{Plaice}

\section{Lemon sole}

baseline trawl, small individuals $(5-15 \mathrm{~cm})$ entered the lower compartment in greater numbers, although the result was only significant in Experiment 1. In contrast, whiting belonging to the main bulk of data $(20-30 \mathrm{~cm})$ had a strong preference for the upper compartment in the baseline trawl of both experiments. The light treatment did not improve the vertical separation of whiting in either experiment. With the lights in the lower panel (Experiment 1), whiting had a more uniform distribution, with no preference for the upper compartment, and the difference was significant for individuals of $20-23 \mathrm{~cm}$ (Fig. 5, Delta). In Experiment 2, the lights in the upper panel negatively affected individuals between 16 and $22 \mathrm{~cm}$, which were caught significantly more in the lower compartment.

The separation efficiency curves of both the baseline and test trawls described the experimental data for plaice belonging to the main interval of the length classes relatively well (20-40 cm; Fig. 6). A relatively large proportion of plaice were caught in the upper compartment, but overall there was a uniform vertical distribution, with the $\mathrm{Cls}$ for all length-classes overlapping the horizontal line representing an equal preference for either compartment (Fig. 6). LED lights in the lower compartment (Experiment 1) significantly and negatively affected plaice of $23-32 \mathrm{~cm}$ (Fig. 6, Delta). Lights in the upper compartment did not cause significant changes in the vertical separation efficiency. 
Few lemon sole were caught during the experiments; however, the separation efficiency curves represented the experimental data well (Fig. 7) and the fit statistics indicated that the models could be trusted. In the baseline trawl, lemon sole had a uniform distribution, and thus, according to the size of the entrances of the compartments, entered the upper compartment in greater numbers. No change in the vertical separation efficiency was observed when lights were attached to the lower netting panel (Experiment 1), whereas small lemon sole of $17-21 \mathrm{~cm}$ were significantly affected by lights in the upper netting panel (Experiment 2), resulting in a preference for the lower compartment (Fig. 7, Delta).

FIGURE 7

\section{Discussion}

Several stimuli contribute in determining species vertical distribution in the trawl extension. Sound, vibrations, intra- and inter-species interactions, visible background and state of fatigue due to the first part of the catching process, as well as individual physical constrains, have been described to influence species separation (Winger et al., 2010; Fryer et al., 2017). When testing lights, these confounding factors often complicate the interpretation of results and limit the inference of species-specific behavioural responses. The methodology applied in this study accounted for the variability introduced by other factors than the device tested by towing the baseline and test trawls in parallel. Unfortunately, we could not account for interactions between the light treatment and other factors or determine which of the parameters of the light (e.g. intensity, colour, orientation) was the main driver of the response. In this study, we aimed at investigating if phototaxis could be exploited to modify fish vertical distribution and if either positive or negative phototaxis could be efficient in leading fish into the upper compartment. We 
found that LED lights in the trawl extension had significant effects on the vertical distribution of the species investigated. However, we could not conclude these changes were caused by phototactic responses, i.e. movements directed towards or away from the lights. .

LED lights in the lower panel increased small cod $(11-18 \mathrm{~cm})$ preference for the lower compartment, while medium-sized cod $(28-43 \mathrm{~cm})$ lost the preference for the upper compartment observed in the baseline trawl. Similarly, whiting $(20-23 \mathrm{~cm})$ shifted from a clear preference for the upper compartment in the baseline trawl to a uniform distribution with LED lights in the lower panel. Small plaice $(23-32 \mathrm{~cm})$ were uniformly distributed in the baseline trawl, whereas showed a preference for the lower compartment in the test trawl. Surprisingly, Nephrops between 40 and $55 \mathrm{~mm}$ showed a significant increased preference for the lower compartment in the test trawl. This species usually has a weakly length-dependent vertical separation, with a higher percentage of individuals above $50 \mathrm{~mm}$ (carapace length) entering the upper compartment (Karlsen et al., 2015; Graham and Fryer, 2006). Because these individuals would be lost in a compartment with large meshes, i.e. the upper compartment, the potential positive phototaxis observed in this study might be of interest to reduce the loss of the target species.

These responses, despite being apparently directed towards the lights, should not be interpreted as positive phototaxis. When testing the lights in the opposite position (upper netting panel) we did not obtain inverted effects respect to those observed in Experiment 1. On the contrary, some species still entered in higher numbers the lower compartment. For example, small whiting $(16-22 \mathrm{~cm})$ and small lemon sole $(15-21 \mathrm{~cm})$ were both found 
in higher numbers in the lower compartment in the test trawl. However, small whiting were only slightly affected by the lights, partly losing their preference for the upper compartment, whereas small lemon sole had a strong preference for the lower compartment when exposed to lights in the upper panel. In contrast, haddock between 33 and $42 \mathrm{~cm}$ developed a strong preference for the upper compartment in response to the lights.. Unfortunately, no data were collected for Nephrops in Experiment 2, and thus any influence of lights in the upper panel on large individuals remains unknown.

According to the results, species-specific phototactic responses were not clearly identified. Each species seemed to react mainly to one treatment position, showing only a tendency or no response to the other. Most of the significant changes in vertical distribution could be attributed to an increased awareness of the surroundings, panic or species-specific escape behaviours. For example, many demersal species have a tendency to move towards the seafloor when threatened (Winger et al., 2010; Gibson, 2014). Unfortunately, the lack of understanding of which parameters of the lights are the main drivers of species responses limit the inferential power of this type of study. For example, we cannot exclude that the lack of response to one of the light treatment position was determined by a difference in intensity of the stimulus between the two experiments, considering that when attached to the lower panel the lights were partly obscured by the sediment resuspension. The actual light intensity during towing might have strong consequences on the type of reaction obtained as species adapted to low light levels are likely to be blinded or disoriented by artificial lights. Moreover, with lights such as the Electralume, which don't emit light in all directions, the orientation of the lights may affect species perception of the stimulus. Fish's swimming direction in the trawl funnel, either 
towards the codend or in the towing direction, varies because of fatigue, interaction with other individuals, and panic (Winger et al., 2010). Accordingly, smaller individuals might be more frequently oriented towards the codend, because their limited swimming capacity would lead to physical exhaustion (He, 1993; Winger et al., 2010). Furthermore, species-specific preferred orientations have been described, in particular among flatfish (Winger et al., 2010)

The results obtained in this study indicate that the reaction of selected species to artificial lights and the factors involved in determining the type and strength of the reaction require further study. In particular, the physical parameters of the light such as intensity, colour, orientation, and position should be tested systematically under controlled laboratory conditions before attempting further applications inside a trawl. Without understanding the drivers of the behaviour, even positive results might be inconsistent over time and space since commercial fisheries operate in highly variable conditions. Despite the success obtained with lights in static fisheries (Nguyen et al., 2017; Wang et al., 2010) and in the forward part of the trawl (Hannah et al., 2015), their attempted application inside trawls have mostly failed to achieve the expected results. In our study, as well as in previous studies (Grimaldo et al., 2017; Larsen at al., 2017; Hannah et al., 2015), green LED lights were not only useless as a bycatch reduction measure, but had a negative effect on the vertical distribution of fish, increasing the amount of fish entering the lower compartment together with Nephrops. Therefore, these lights do not currently represent a solution to improve fish separation from Nephrops in the Nephrops-directed mixed trawl fishery. Mechanical stimulations might be more efficient in rising flatfish and small roundfish, which according to the results of this study are the two groups whose separation still 
484

485

486

487

488

489

490

491

492

493

494

495

496

497

498

499

500

501

502

503

504

needs to be improved. Nonetheless, artificial lights as a behavioural stimulation during the fishing process shows great potential for future application, once a more mechanistic understanding of light and behaviour is acquired. In this study, all species investigated responded to the lights, even the juveniles, which are known to have a limited swimming capacity. These behavioural responses might be applicable to reduce bycatch in fisheries elsewhere.

\section{Acknowledgements}

This study has received funding from the European Maritime and Fisheries Fund (https://ec.europa.eu/fisheries/cfp/emff en) and the Ministry of Environment and Food of Denmark. Project: Vision - Development of an optimal and flexible selective system for trawl by use of new technology and underexploited fish behaviour (Grant Agreement No 33113-|-16-015).

\section{References}

Akaike, H., 1974. A new look at the statistical model identification. IEEE Transactions on Automatic Control, 19: 716-722. doi:10.1109/TAC.1974.1100705

Anthony, P. D., and Hawkins, A. D., 1983. Spectral sensitivity of the cod, Gadus morhua L. Marine \& Freshwater Behaviour \& Phy, 10(2): 145-166. doi:10.1080/10236248309378614

Arimoto, T., Glass, C., and Zhang, X., 2010. Fish vision and its role in fish capture. In: Behaviour of marine fishes: Capture process and conservation challenges. Edited by P. He. Blackwell Publishing Ltd. lowa, USA. pp 25-40. ISBN: 978-0-8138-1536-7

Ben-Yami, M., 1976. Fishing with light. In: FAO of the United Nations. Fishing News Books, Oxford. 
Bryhn, A. C., Königson, S. J., Lunneryd, S., and Bergenius, M. A. J., 2014. Green lamps as visual stimuli affect the catch efficiency of floating cod (Gadus morhua) pots in the Baltic Sea. Fisheries Research, 157: 187-192. doi: 10.1016/j.fishres.2014.04.012

Burnham, K.P., and Anderson, D.R., 2002. Model Selection and Multimodel Inference: A Practical Information-theoretic Approach, 2nd ed. Springer, New York.

Domenici, P., 2002. The visually mediated escape response in fish: predicting prey responsiveness and the locomotor behaviour of predators and prey. Marine and Freshwater Behaviour and Physiology, 35(1-2): 87-110. doi: 10.1080/10236240290025635

Efron, B., 1982. The jackknife, the bootstrap and other resampling plans. In Society for industrial and applied mathematics (SIAM) Monograph No. 38, CBSM-NSF.

Ferro, R.S.T., Jones, E.G., Kynoch, R.J., Fryer, R.J., and Buckett, B.E., 2007. Separating species using a horizontal panel in the Scottish North Sea whitefish trawl fishery. ICES Journal of Marine Science, 64: 1543-1550. doi: 10.1093/icesjms/fsm099

Frandsen, R.P., Madsen, N., and Krag, L.A., 2010. Selectivity and escapement behaviour of five commercial fishery species in standard square- and diamond-mesh codends. ICES Journal of Marine Science, 67: 1721-1731. doi: 10.1093/icesjms/fsq050

Gibson, R. N., Nash, R. D., Geffen, A. J., and Van der Veer, H. W., 2014. Flatfishes: biology and exploitation. Eds. John Wiley \& Sons.

Glass, C.W., Wardle, C.S., and Gosden, S.J., 1993. Behavioural studies of the principles underlying mesh penetration by fish. In ICES Marine Science Symposia, 196: 92-97.

Graham, N., and Fryer, R.J., 2006. Separation of fish from Nephrops norvegicus into a two-tier codend using a selection grid. Fisheries Research, 82: 111-118. doi: 10.1016/j.fishres.2006.08.011 
527 Grimaldo, E., Sistiaga, M., Herrmann, B., Larsen, R. B., Brinkhof, J., and Tatone, I., 2017. Improving 528 release efficiency of cod (Gadus morhua) and haddock (Melanogrammus aeglefinus) in the Barents Sea demersal trawl fishery by stimulating escape behaviour. Canadian Journal of Fisheries and Aquatic Sciences, (ja). doi: 10.1139/cjfas-2017-0002

Hannah, R. W., Lomeli, M. J. M., and Jones, S. A., 2015. Tests of artificial light for bycatch reduction in an ocean shrimp (Pandalus jordani) trawl: Strong but opposite effects at the footrope and near the bycatch reduction device. Fisheries Research, 170: 60-67. doi: 10.1016/j.fishres.2015.05.010 Symposia, 196: 183-189. multispecies trawls. Journal of Ocean Technology, 3: 60-77. selectivity of redfish (Sebastes spp.) in North Atlantic trawl codends. Journal of Northwest Atlantic changes on catch efficiency: Methodology and a case study for a Spanish longline fishery targeting Japan. Journal of the Illuminating Engineering Institute of Japan, 91(4): 199-209. 
e0140864.

Katsanevakis, S., 2006. Modeling fish growth: Model selection, multi-model inference and model selection uncertainty. Fisheries Research, 81: 229-235. doi:10.1016/j.fishres.2006.07.002

Kelleher, K., 2005. Discards in the world's marine fisheries: an update. FAO Fisheries Technical Paper No. 470. Food and Agriculture Organization of the United Nations, Rome, Italy.

Krag, L.A., Frandsen, R.P., and Madsen, N., 2008. Evaluation of a simple means to reduce discard in the Kattegat-Skagerrak Nephrops (Nephrops norvegicus) fishery: commercial testing of different codends and square-mesh panels. Fisheries Research, 91: 175-186. doi:10.1016/j.fishres.2007.11.022

Krag, L.A., Holst, R., and Madsen, N., 2009. The vertical separation of fish in the aft end of a demersal trawl. ICES Journal of Marine Science, 66(4): 772-777. doi:10.1093/icesjms/fsp034

561

562

Larsen, R. B., Herrmann, B., Sistiaga, M., Brinkhof, J., Tatone, I., and Langård, L., 2017. Performance

Krag, L.A., Herrmann, B., and Karlsen, J.D., 2014. Inferring fish escape behaviour in trawls based on catch comparison data: model development and evaluation based on data from Skagerrak, Denmark. PLOS ONE 9(2), e88819. doi:10.1371/journal.pone.0088819

Krag, L.A., Herrmann, B., Karlsen, J.D., and Mieske, B. 2015. Species selectivity in different sized topless trawl designs: Does size matter? Fisheries Research, 172: 243-249. doi:10.1016/j.fishres.2015.07.010

of the Nordmøre Grid in Shrimp Trawling and Potential Effects of Guiding Funnel Length and Light Stimulation. Marine and Costal Fisheries, 9(1). doi: 10.1080/19425120.2017.1360421 
570 Lomeli, M. J., and Wakefield, W. W., 2014. Examining the potential use of artificial illumination to 571 enhance Chinook salmon escapement out a bycatch reduction device in a Pacific hake midwater trawl. NMFS Northwest Fisheries Science Center Report.

Main, J., and Sangster, G.I., 1985a. Trawling experiments with a two-level net to minimise the undersized gadoid bycatch in a Nephrops fishery. Fisheries Research, 3: 131-145. doi: $10.1016 / 0165-7836(85) 90014-1$

Main, J., and Sangster, G.I., 1985b. The behaviour of the Norway Lobster, Nephrops norvegicus

577 (L.), during trawling. Scottish Fishery Research Report No. 34. Department of Agriculture and $578 \quad$ Fisheries for Scotland. Aberdeen. pp. 23.

580 light on fish species of commercial interest. Fisheries Research, 73(1): 171-185. doi: $581 \quad$ 10.1016/j.fishres.2004.12.009

582 Melli, V., Karlsen, J. D., Feekings, J. P., Herrmann, B., \& Krag, L. A., 2017. FLEXSELECT: counter583 herding device to reduce bycatch in crustacean trawl fisheries. Canadian Journal of Fisheries and 584 Aquatic Sciences, (ja). doi: 10.1139/cjfas-2017-0226

585 Millar, R.B., 1993. Incorporation of between-haul variation using bootstrapping and 586 nonparametric estimation of selection curves. Fishery Bulletin, 91: 564-572.

587 Nguyen, K. Q., and Tran, P. D., 2015. Benefits of using LED light for purse seine fisheries: A case 588 study in Ninh Thuan Province, Vietnam. Fish for the People, 13(1): 30-36.

589 Nguyen, K. Q., Winger, P. D., Morris, C., and Grant, S. M., 2017. Artificial lights improve the 590 catchability of snow crab (Chionoecetes opilio) traps. Aquaculture and Fisheries. doi: $591 \quad 10.1016 /$ j.aaf.2017.05.001 
Pascoe, P.L., 1990. Light and the capture of marine animals. In: Herring, P.J. (Ed.), Light and Life in the Sea. Cambridge University Press, Cambridge, UK, pp. 229-244.

Ryer, C. H., Stoner, A. W., Iseri, P. J., and Spencer, M. L., 2009. Effects of simulated underwater vehicle lighting on fish behavior. Marine Ecology Progress Series, 391: 97-106. doi: $10.3354 /$ meps08168

Rosen, S., Engås, A., Fernö, A., and Jörgensen, T., 2012. The reactions of shoaling adult cod to a pelagic trawl: implications for commercial trawling. ICES journal of marine science, 69(2): 303-312. doi: 10.1093/icesjms/fsr199

Verheijen, F. J., 1960. The mechanisms of the trapping effect of artificial light sources upon animals. Archives Néerlandaises de Zoologie, 13(1): 1-107.

Wang, J. H., Fisler, S., and Swimmer, Y., 2010. Developing visual deterrents to reduce sea turtle bycatch in gill net fisheries. Marine Ecology Progress Series, 408: 241-250. doi: 10.3354/meps08577

Wileman, D. A., Ferro, R. S. T., Fonteyne, R., and Millar, R. B., 1996. Manual of Methods of Measuring the Selectivity of Towed Fishing Gears. ICES Cooperative Research Report No. 215, ICES, Copenhagen, Denmark.

Winger, P.D., Eayrs, S., and Glass, C.W., 2010. Fish behaviour near bottom trawls. In He, P. (Ed.), Behavior of marine fishes: capture processes and conservation challenges, pp. 67-102. WileyBlackwell, Arnes, IA. 
614

615

616

617

618

619

620

621

$622 \quad$ Figures 


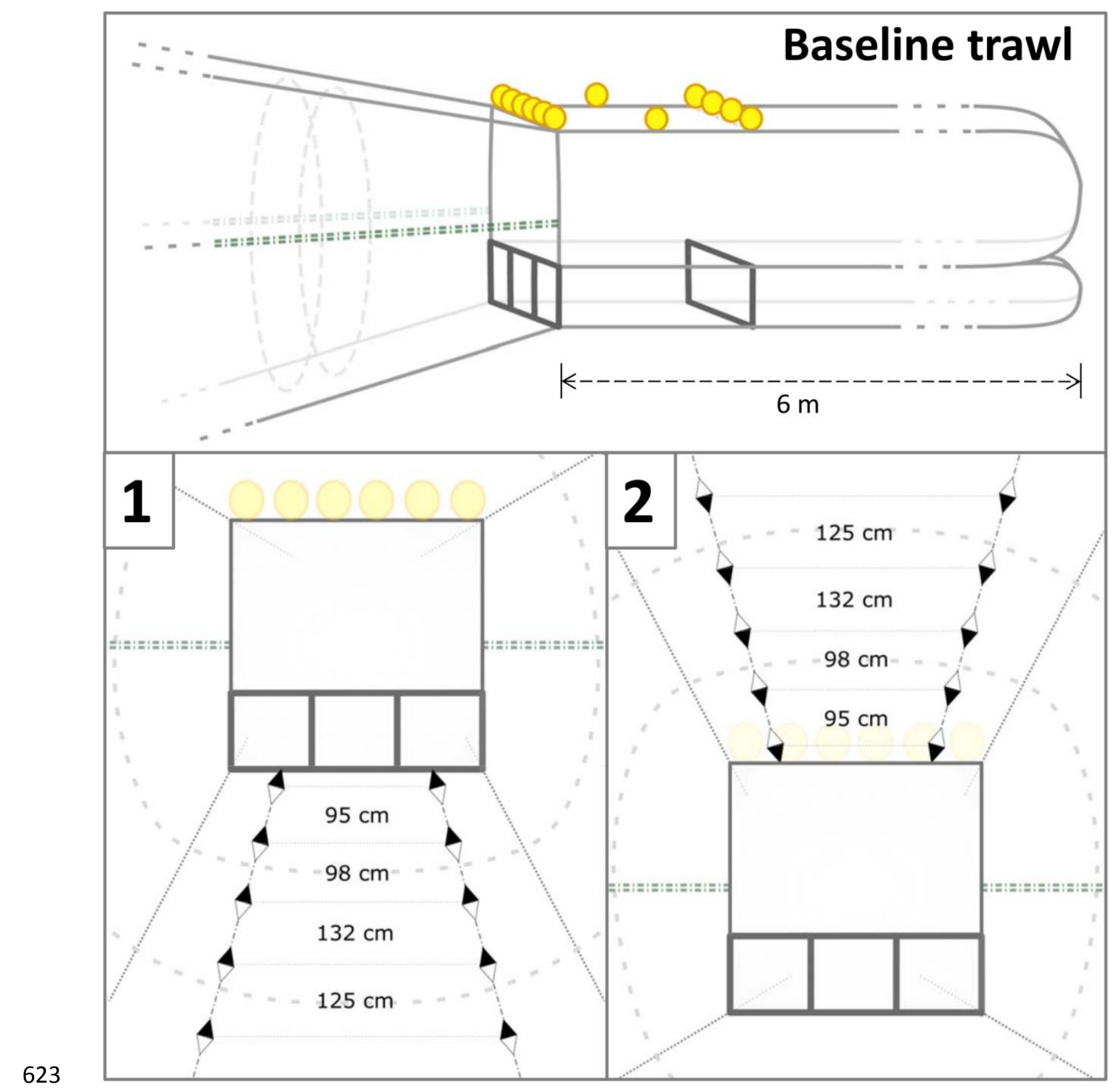

624 Figure 1. Schematic illustration of the baseline trawl and the position of the lights in experiment 1 and 2.

625 The dot-dash double lines represent the selvages. LED lights are represented with the white triangle 626 indicating the direction of the light emitted. To facilitate the identification of all the components the 627 proportions shown are not accurate. 


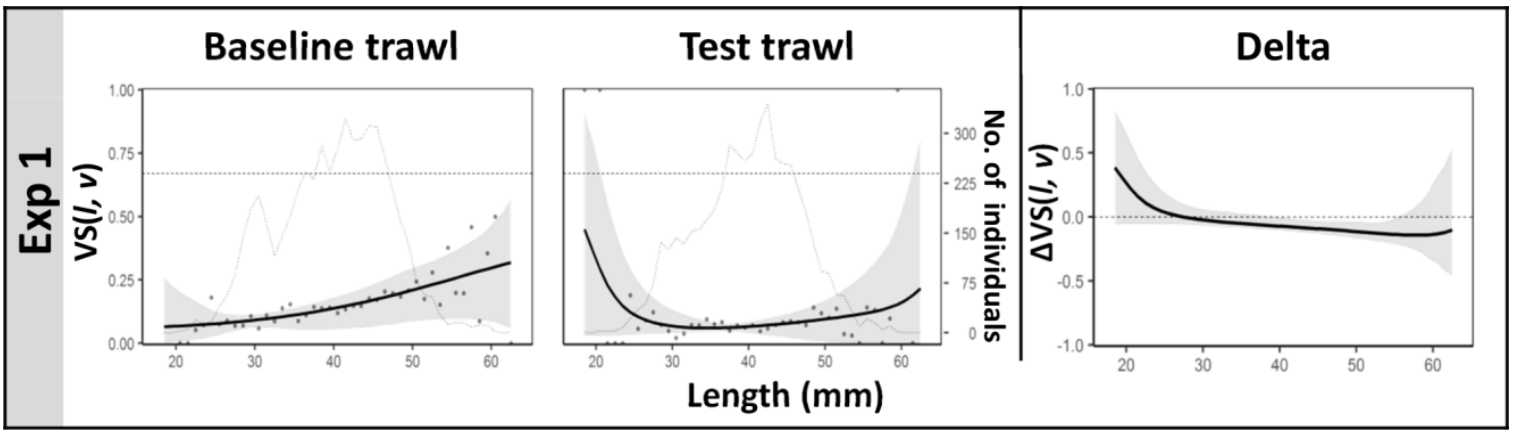

Figure 2. The VS $(I, v)$ for Nephrops in the baseline and test trawls, and $\Delta V S(I, v)$. In the first two columns, the curve (solid line) represents the modelled VS fitted to the experimental points (dots). The grey bands are the $95 \% \mathrm{Cls}$ and the dotted line is the length distribution of the data. The dashed horizontal line, located at 0.67 , describes an equal preference for entering either compartment. In the third column, the solid line represents the difference in VS between the baseline and test trawls, accounting for synchronized hauls.

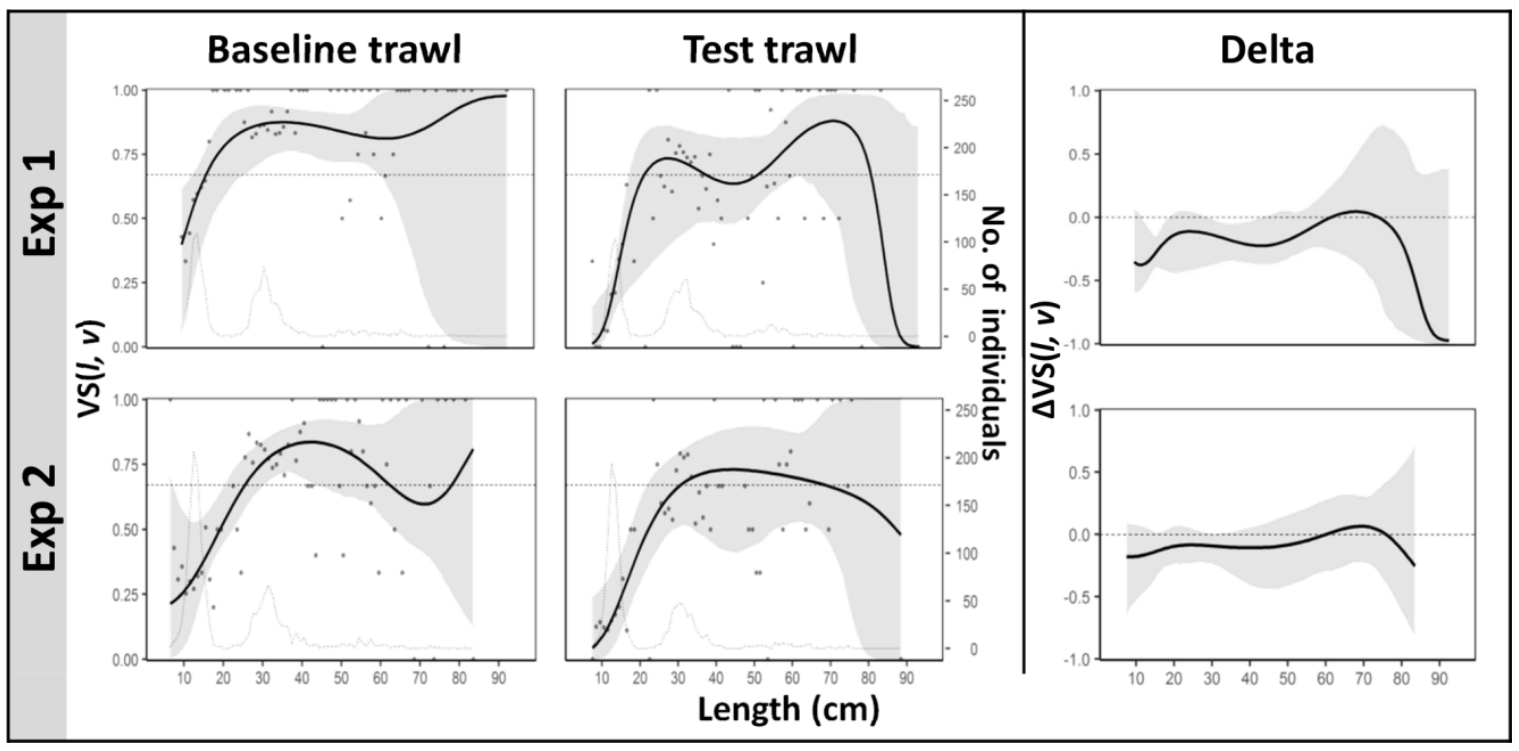

Figure 3. The $V S(I, v)$ for cod in the baseline and test trawls, and $\Delta V S(I, v)$. In the first two columns, the curve

637 (solid line) represents the modelled VS fitted to the experimental points (dots). The grey bands are the 95\%

Cls and the dotted line is the length distribution of the data. The dashed horizontal line, located at 0.67 , describes an equal preference for entering either compartment. In the third column, the solid line represents the difference in VS between the baseline and test trawls, accounting for synchronized hauls. 


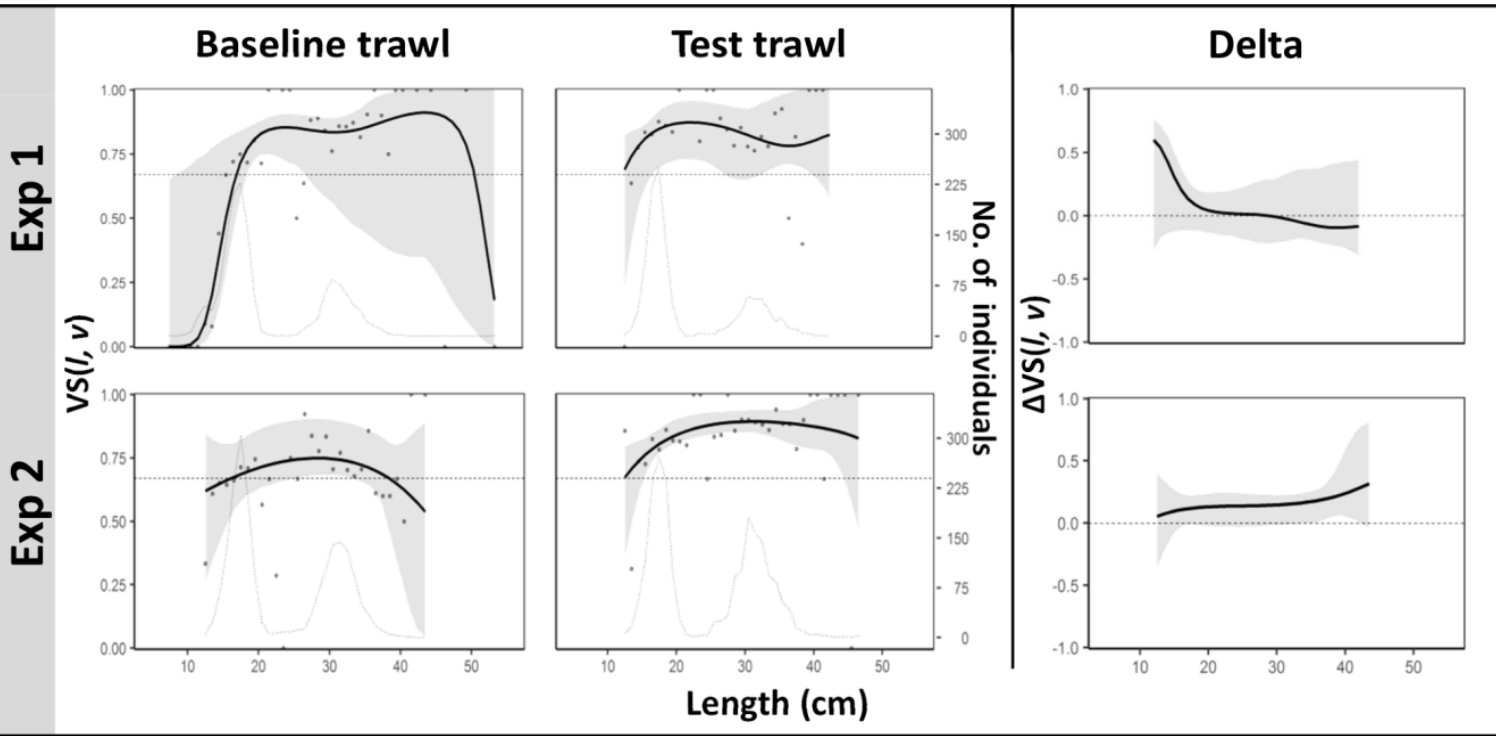

Figure 4. The $V S(I, v)$ for haddock in the baseline and test trawls, and $\Delta V S(I, v)$. In the first two columns, the curve (solid line) represents the modelled VS fitted to the experimental points (dots). The grey bands are the $95 \% \mathrm{Cls}$ and the dotted line is the length distribution of the data. The dashed horizontal line, located at 0.67, describes an equal preference for entering either compartment. In the third column, the solid line represents the difference in VS between the baseline and test trawls, accounting for synchronized hauls.

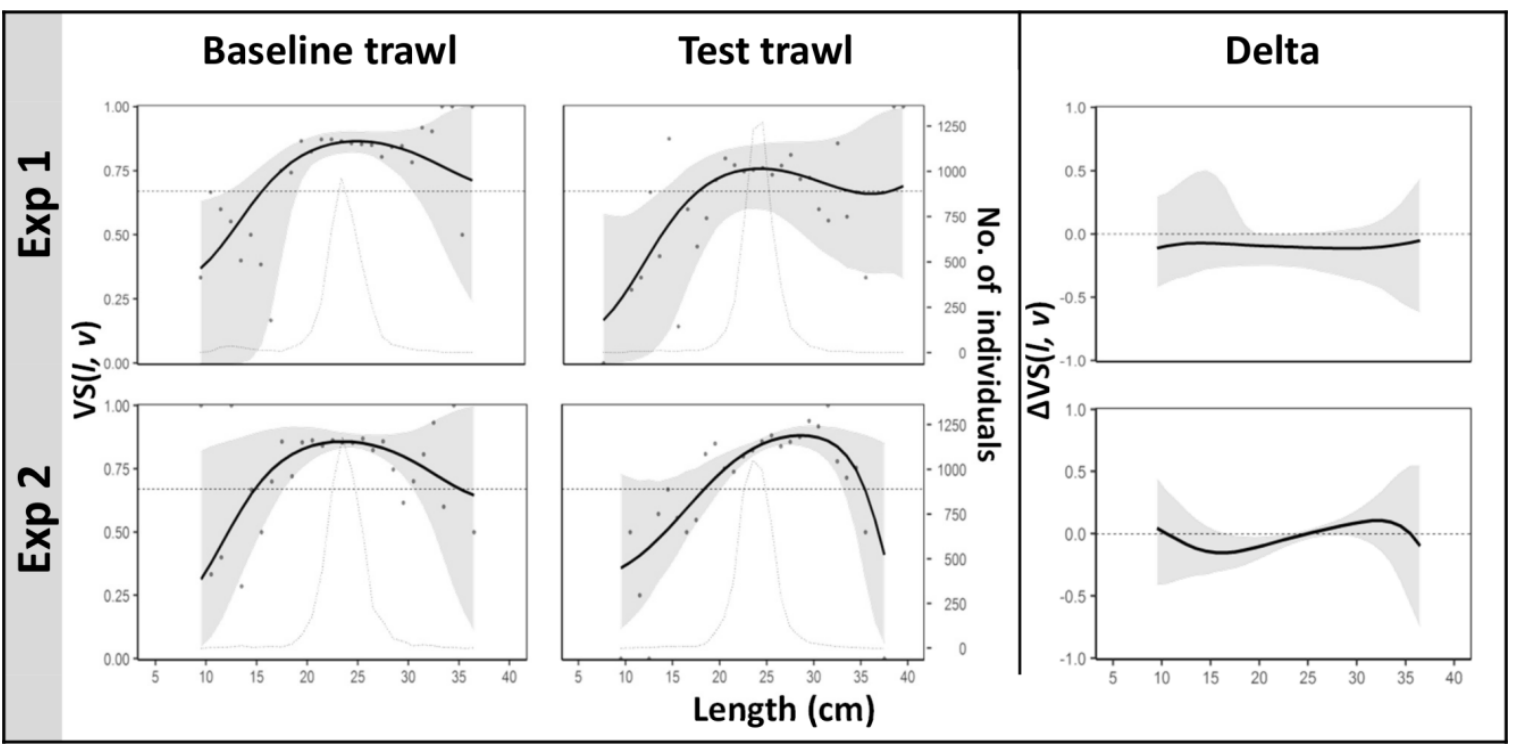

Figure 5. The $\operatorname{VS}(I, v)$ for whiting in the baseline and test trawls, and $\Delta V S(I, v)$. In the first two columns, the curve (solid line) represents the modelled VS fitted to the experimental points (dots). The grey bands are the $95 \% \mathrm{Cls}$ and the dotted line is the length distribution of the data. The dashed horizontal line, located at 


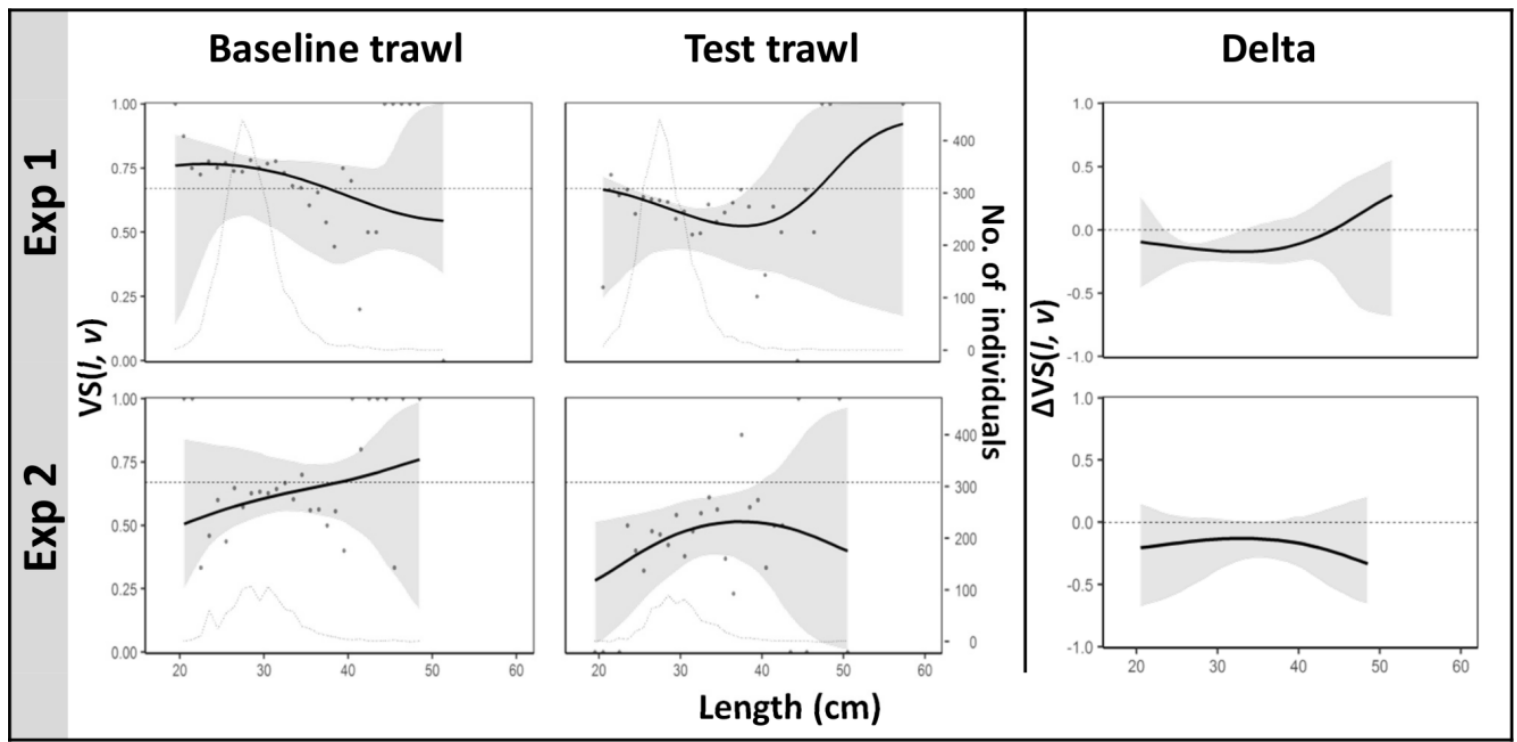

Figure 6. The $V S(I, v)$ of plaice in the baseline and test trawls, and $\Delta \mathrm{VS}(I, \boldsymbol{v})$. In the first two columns, the curve (solid line) represents the modelled VS fitted to the experimental points (dots). The grey bands are the $95 \% \mathrm{Cls}$ and the dotted line is the length distribution of the data. The dashed horizontal line, located at 0.67, describes an equal preference for entering either compartment. In the third column, the solid line represents the difference in VS between the baseline and test trawls, accounting for synchronized hauls.

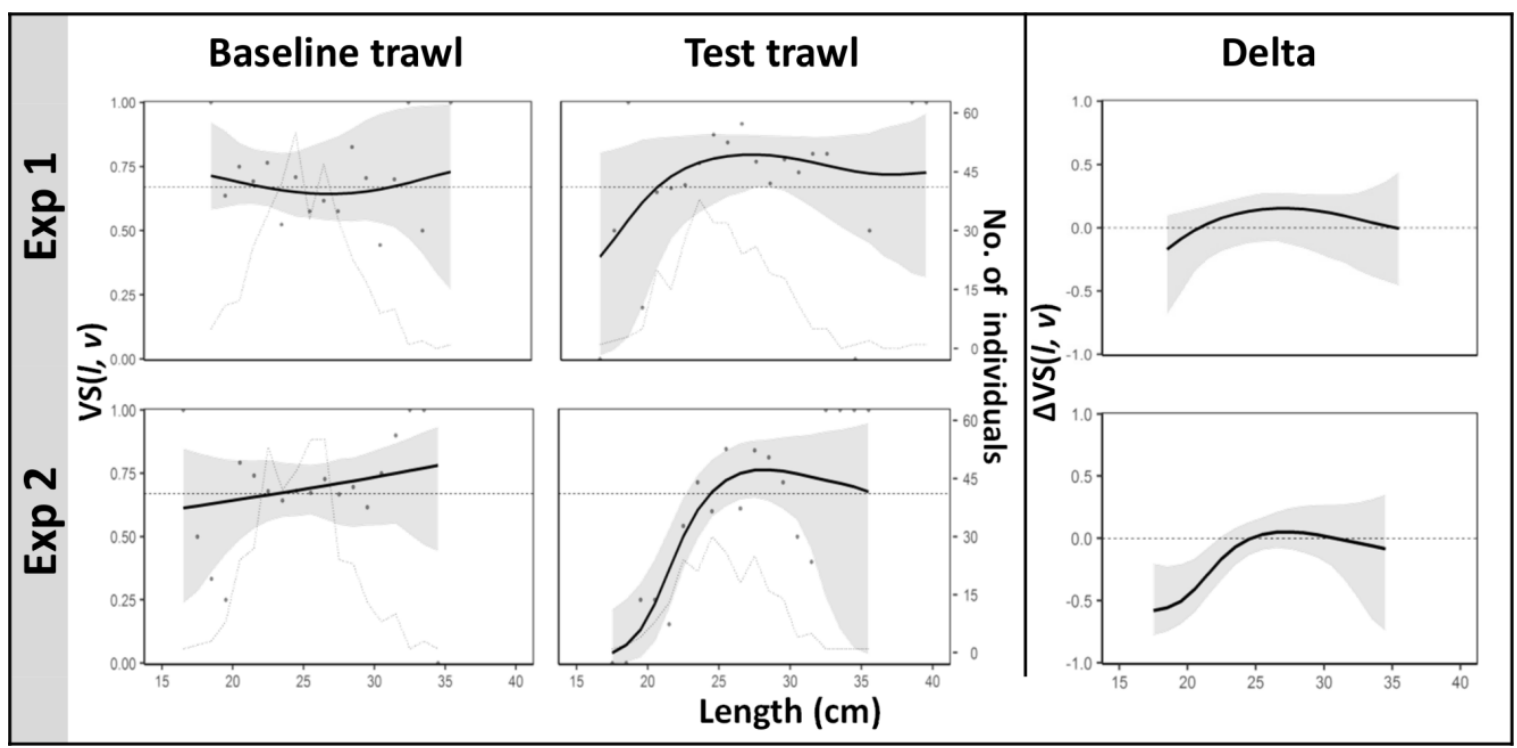


664 Figure 7. The $\mathrm{VS}(I, v)$ of lemon sole in the baseline and test trawls, and $\Delta \mathrm{VS}(I, \boldsymbol{v})$. In the first two columns,

665 the curve (solid line) represents the modelled VS fitted to the experimental points (dots). The grey bands

666 are the $95 \% \mathrm{Cls}$ and the dotted line is the length distribution of the data. The dashed horizontal line, located at $\mathbf{0 . 6 7}$, describes an equal preference for entering either compartment. In the third column, the solid line represents the difference in VS between the baseline and test trawls, accounting for synchronized hauls.

669 The grey bands are the $95 \% \mathrm{Cls}$ and the dashed line represents no difference in VS.

670

671

672

673

674

675

676

677

678

679

680

681

682

683

684 
Table 1. Overview of the experimental hauls, showing the technical and environmental parameters and

687 total catch $(\mathrm{kg})$ for each of the four compartments. $\mathrm{BU}=$ baseline upper compartment; $\mathrm{BL}=$ baseline lower

688 compartment; $\mathrm{TU}=$ test upper compartment; $\mathrm{TL}=$ test lower compartment. Hauls were separated in Port trawl (P).

691

\begin{tabular}{|cccccccccccc|}
\hline $\begin{array}{c}\text { Haul } \\
\text { No. }\end{array}$ & Exp. & $\begin{array}{c}\text { Test } \\
\text { trawl }\end{array}$ & $\begin{array}{c}\text { Start time } \\
\text { (hh:mm) }\end{array}$ & $\begin{array}{c}\text { Towing time } \\
\text { (hh:mm) }\end{array}$ & $\begin{array}{c}\text { Depth } \\
\text { (m) }\end{array}$ & $\begin{array}{c}\text { Wind } \\
\text { (m/s) }\end{array}$ & $\begin{array}{c}\text { Speed } \\
\text { (kn) }\end{array}$ & $\begin{array}{c}\text { BU } \\
\text { (kg) }\end{array}$ & $\begin{array}{c}\text { BL } \\
(\mathbf{k g})\end{array}$ & $\begin{array}{c}\text { TU } \\
(\mathbf{k g})\end{array}$ & $\begin{array}{c}\text { TL } \\
\text { (kg) }\end{array}$ \\
\hline \hline 1 & 1 & $\mathrm{P}$ & $05: 35$ & $00: 30$ & 86 & 3 & 2.8 & 99 & 145 & 181 & 285 \\
2 & 1 & $\mathrm{P}$ & $07: 50$ & $00: 50$ & 84 & 3 & 2.8 & 735 & 410 & 825 & 474 \\
3 & 1 & $\mathrm{P}$ & $01: 45$ & $00: 30$ & 77 & 3 & 2.9 & 170 & 126 & 230 & 178 \\
4 & 1 & $\mathrm{~S}$ & $05: 05$ & $00: 30$ & 82 & 3 & 2.9 & 244 & 113 & 70 & 140 \\
5 & 1 & $\mathrm{~S}$ & $08: 25$ & $00: 45$ & 80 & 2 & 2.9 & 219 & 175 & 120 & 155 \\
6 & 1 & $\mathrm{~S}$ & $11: 20$ & $00: 45$ & 84 & 2 & 2.9 & 480 & 200 & 226 & 176 \\
7 & 1 & $\mathrm{~S}$ & $14: 35$ & $01: 30$ & 54 & 2 & 2.9 & 24 & 106 & 61 & 110 \\
8 & 1 & $\mathrm{~S}$ & $08: 10$ & $01: 30$ & 46 & 1 & 2.6 & 73 & 155 & 76 & 148 \\
9 & 1 & $\mathrm{~S}$ & $12: 40$ & $01: 00$ & 45 & 0 & 2.6 & 22 & 33 & 30 & 61 \\
10 & 1 & $\mathrm{~S}$ & $14: 25$ & $01: 00$ & 48 & 0 & 2.6 & 17 & 52 & 42 & 63 \\
\hline \hline 11 & 2 & $\mathrm{P}$ & $08: 20$ & $00: 45$ & 77 & 5 & 2.9 & 415 & 175 & 180 & 170 \\
12 & 2 & $\mathrm{P}$ & $12: 40$ & $00: 45$ & 86 & 6 & 2.9 & 385 & 230 & 205 & 230 \\
13 & 2 & $\mathrm{P}$ & $16: 05$ & $00: 45$ & 85 & 7 & 2.9 & 127 & 140 & 240 & 240 \\
14 & 2 & $\mathrm{P}$ & $20: 40$ & $00: 45$ & 85 & 7 & 2.9 & 130 & 181 & 275 & 174 \\
15 & 2 & $\mathrm{P}$ & $23: 30$ & $00: 45$ & 86 & 6 & 2.9 & 60 & 147 & 80 & 52 \\
16 & 2 & $\mathrm{P}$ & $17: 24$ & $00: 30$ & 86 & 6 & 2.9 & 117 & 130 & 241 & 147 \\
17 & 2 & $\mathrm{~S}$ & $21: 08$ & $00: 45$ & 83 & 4 & 2.9 & 115 & 163 & 120 & 172 \\
18 & 2 & $\mathrm{~S}$ & $00: 00$ & $00: 45$ & 84 & 8 & 2.9 & 177 & 117 & 158 & 145 \\
\hline
\end{tabular}

692

693

694

695

696

697

698

699 
Table 2. Number of hauls and number of individuals per species per compartment included in the analyses of each experiment, 1 and 2. $U$ = upper compartment; $L=$ lower compartment. Species that were

703 subsampled are indicated with the raised total number and the actual number of individuals measured (in 704 brackets).

705

\begin{tabular}{|cccccc|}
\hline \multicolumn{7}{c}{ Experiment 1 } & \multicolumn{2}{c|}{ Test trawl } \\
& Hauls & $\mathrm{nU}$ & $\mathbf{n L}$ & $\mathrm{nU}$ & $\mathrm{nL}$ \\
Nephrops & 4 & 782 & $4688(2545)$ & 371 & $4675(2466)$ \\
Cod & 8 & 707 & 256 & 508 & 463 \\
Haddock & 6 & 1040 & 453 & 1017 & 203 \\
Whiting & 10 & $3398(2803)$ & 627 & 3858 & 1293 \\
Plaice & 6 & 2244 & 760 & 1758 & 1186 \\
Lemon sole & 6 & 238 & 123 & 219 & 70 \\
\hline & \multicolumn{7}{c}{ Experiment 2 } & \multicolumn{2}{c|}{ Test trawl } \\
\hline \hline & Bauls & $\mathrm{nU}$ & $\mathbf{n L}$ & $\mathrm{nU}$ & $\mathrm{nL}$ \\
Nephrops & - & - & - & - & - \\
Cod & 8 & 724 & 718 & 425 & 759 \\
Haddock & 8 & 1402 & 582 & 1812 & 334 \\
Whiting & 8 & $4261(2920)$ & 766 & $4053(3584)$ & 859 \\
Plaice & 8 & 568 & 377 & 313 & 366 \\
Lemon sole & 7 & 275 & 125 & 136 & 79 \\
\hline
\end{tabular}

706

707

708

709

710

711

712

713

714

715 
716 Table 3. Fit statistics for the modelled vertical separation efficiencies. DoF denotes the degree of freedom

717 and was calculated by subtracting the number of model parameters from the number of length classes in

718 the dataset.

\begin{tabular}{|c|c|c|c|c|c|c|}
\hline \multicolumn{7}{|c|}{ Experiment 1} \\
\hline & \multicolumn{3}{|c|}{ Baseline trawl } & \multicolumn{3}{|c|}{ Test trawl } \\
\hline & $p$-value & Deviance & DoF & $p$-value & Deviance & DoF \\
\hline Nephrops & 0.80 & 29.56 & 37 & 0.01 & 59.03 & 37 \\
\hline Cod & 0.43 & 57.19 & 56 & 0.02 & 81.63 & 58 \\
\hline Haddock & 0.02 & 50.27 & 32 & 0.18 & 28.96 & 23 \\
\hline Whiting & 0.02 & 38.77 & 23 & 0.08 & 34.17 & 24 \\
\hline Plaice & 0.24 & 30.81 & 26 & 0.33 & 26.51 & 24 \\
\hline Lemon sole & 0.07 & 19.87 & 12 & 0.32 & 17.99 & 16 \\
\hline \multicolumn{7}{|c|}{ Experiment 2} \\
\hline & \multicolumn{3}{|c|}{ Baseline trawl } & \multicolumn{3}{|c|}{ Test trawl } \\
\hline & $p$-value & Deviance & DoF & $p$-value & Deviance & DoF \\
\hline Nephrops & - & - & - & - & - & - \\
\hline Cod & 0.16 & 74.03 & 63 & 0.26 & 57.57 & 51 \\
\hline Haddock & $<0.01$ & 58.23 & 26 & 0.03 & 45.84 & 30 \\
\hline Whiting & $<0.01$ & 40.69 & 22 & 0.02 & 39.03 & 23 \\
\hline Plaice & 0.08 & 33.28 & 23 & 0.07 & 33.85 & 23 \\
\hline Lemon sole & 0.17 & 18.77 & 14 & 0.31 & 16.11 & 14 \\
\hline
\end{tabular}

